\title{
MÉTODO DE DESENVOLVIMENTO DE PRODUTOS DE BAIXA COMPLEXIDADE
}

Daniel Ferreira Teixeira (danielteixeira.mec@gmail.com) - Escola de Engenharia / Universidade Federal de Minas Gerais

Eduardo Romeiro Filho (edu.romeiro@gmail.com) - Universidade Federal de Minas Gerais

\section{RESUMO}

Este trabalho elabora um método para o desenvolvimento de produtos de baixa complexidade, voltado para aplicação em pequenas empresas industriais. Ao estudar duas abordagens de processos de desenvolvimento de produtos (PDP), uma clássica e outra contemporânea, constatou-se a oportuidade de adaptá-las a produtos com número limitado de componentes e processos de fabricação e que são desenvolvidos por equipes enxutas em reduzido espaço de tempo. Antes de desenvolver o método, procurou-se entender algumas características do mercado, considerando-se quatro delas fundamentais para determinar o sucesso ou o fracasso de um novo produto: grau de inovação, características de qualidade, preço adequado e tempo de lançamento. Levando-as em consideração, desenvolveu-se um método voltado para pequenas empresas que busca garantir um processo sistematizado de desenvolvimento de produtos, conforme preconizado em processos considerados "clássicos", incorporando aspectos de métodos contemporâneos, particularmente voltados para ambientes de inovação. Este método possui diversas fases distribuídas em dois grandes blocos: "Planejamento" e "Desenvolvimento e Detalhamento", precedidos por uma fase preliminar ao projeto, a "Identificação de uma Dor de Mercado".

Palavras chave: processo de desenvolvimento de produtos; produtos de baixa complexidade; metodologia de projeto 


\section{INTRODUÇÃ̃O}

O desenvolvimento metodologias de projeto de produtos industriais tem sido um problema bastante estudado nas últimas décadas, seja nas áreas de engenharia como do design, entre outras áreas de projeto. Dentre os primeiros trabalhos a respeito pode-se citar trabalho de JONES (1970), que foi seguido por numerosos estudos em design e engenharia, visando principalmente a estruturação de processos criativos voltados ao desenvolvimento de produtos e serviços. Estudos mais recentes voltam-se à criação de ambientes voltados á inovação, particularmente em startups ou no desenvolvimento de serviços.

Uma questão, entretanto, merece atenção no atual momento, particularmente em países denominados "emergentes": como estimular o desenvolvimento de produtos inovadores de baixa complexidade em pequenas empresas, notadamente em ambientes industriais, que não possuem métodos formais de desenvolvimento e requerem processos mais estruturados do que, por exemplo, startups voltadas para o desenvolvimento de serviços ou aplicativos. Uma alternativa apresentada por este trabalho de abordagem conceitual está na combinação de elementos oriundos de métodos consagrados pela literatura (especialmente dos anos 1980 e 90) com alguns princípios de métodos contemporâneos, voltados para a agilização do processo de desenvolvimento, redução do tempo e aumento dos níveis de inovação.

O processo de desenvolvimento de produto (PDP) foi definido por diversos autores sob vários nomes: projeto e desenvolvimento do produto (ULRICH, EPPINGER, 2000), projeto de engenharia (CROSS, 1994) e processo de planejamento e projeto (PAHL, BEITZ, 1996). Conforme Ulrich e Eppinger (Op.Cit), "Projeto e desenvolvimento do produto diz respeito ao conjunto de atividades interdisciplinares que se iniciam com a identificação de requisitos do cliente e terminam com a entrega do produto fabricado ao cliente, passando pela concepção, projeto e fabricação do produto". Sendo assim, um processo de desenvolvimento de produto eficiente garantirá não apenas a qualidade do produto, mas também o seu sucesso por meio de produtos inovadores, de qualidade, com preço adequado e em um curto espaço de tempo, características que determinarão se um novo produto conseguirá seu lugar no mercado.

Logicamente, cada segmento de produto valoriza mais uma característica em detrimento das outras, mas todas são inevitavelmente necessárias e por isso devem ser contempladas no projeto do produto. Ao se tratar de produtos de baixa complexidade, ou seja, daqueles com reduzido número de componentes e processos de fabricação e que são desenvolvidos por equipes enxutas 
em reduzido espaço de tempo, não raro observa-se que esses produtos apresentam baixa qualidade e, consequentemente, baixa sobrevida no mercado. Isso se deve em parte pela desvalorização ou até mesmo o desconhecimento de metodologias de desenvolvimento de produtos. De fato, um estudo de Allen Booz (1982) estimou que quase a metade dos recursos gastos em novos produtos são alocados em produtos mal sucedidos no mercado, visto que, de mais de 13.000 novos produtos de 700 fabricantes dos EUA, aproximadamente um terço deles não obteve sucesso. Em um estudo com 122 inovações de produtos industriais, Cooper (1983) relata que, para cada 100 produtos que foram totalmente desenvolvidos, apenas 60 se tornam sucessos comerciais. Tendo em vista as demandas do mercado atual, o número de produtos de baixa complexidade que não alcançam o sucesso e o pequeno número de referências direcionadas para o desenvolvimento de produtos de baixa complexidade, este trabalho procura responder a seguinte questão: como desenvolver produtos de baixa complexidade de forma a garantir o seu sucesso?

\section{REVISÃO DE LITERATURA}

\subsection{Características do Mercado}

O primeiro passo para desenvolver um produto bem-sucedido é entender algumas características do mercado. Com o aumento da concorrência e da demanda por produtos de menor custo e tecnologicamente avançados, é imperativo que a eficiência do processo de desenvolvimento de produtos seja aumentada. O ciclo de vida dos produtos mostra que, após um crescimento de demanda, há uma saturação do produto no mercado seguido pela queda de vendas (Figura 1). 


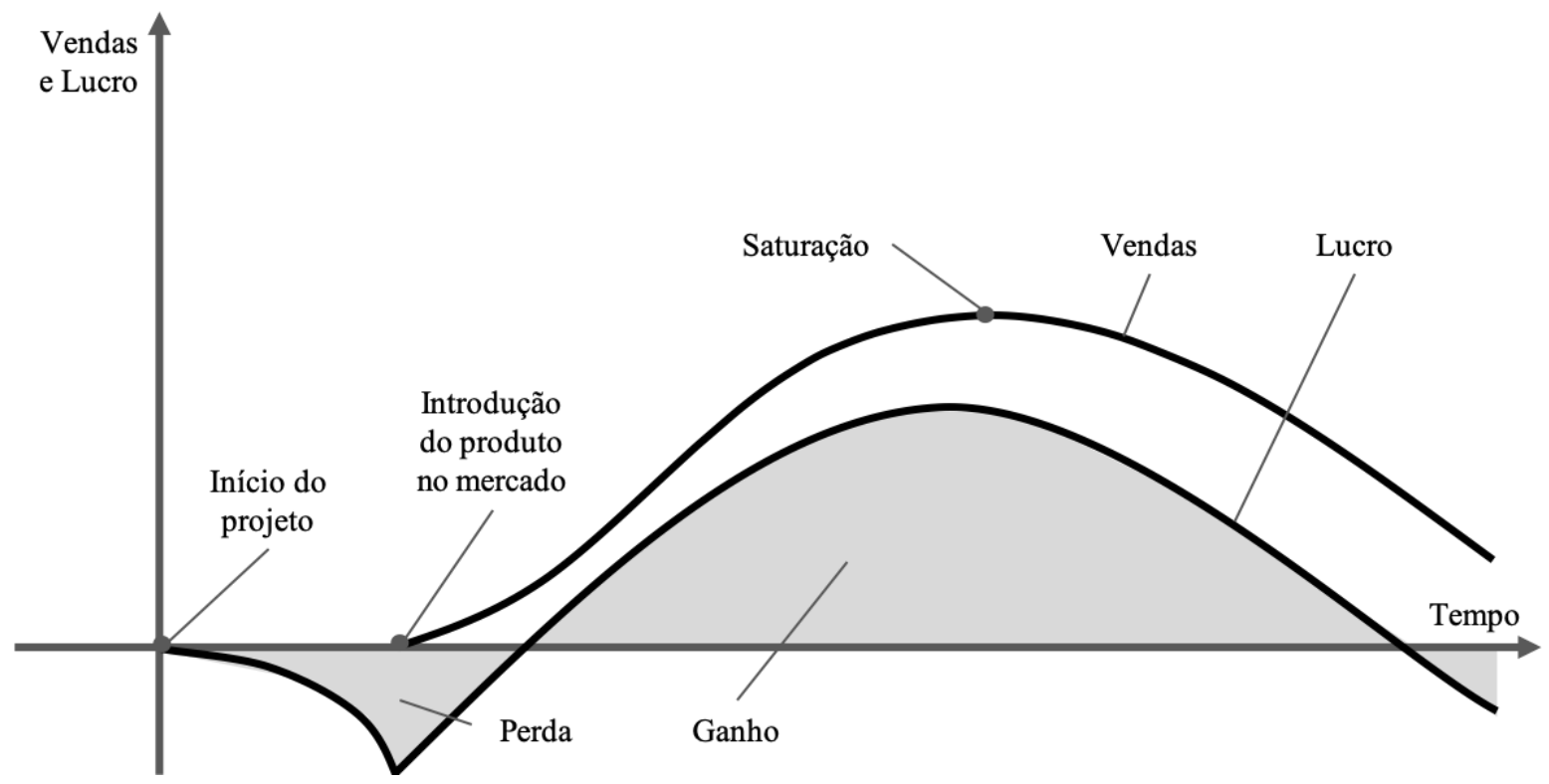

FIGURA 1 - Ciclo de vida de um produto. Fonte: Adaptado de Pahl, Beitz, et al. (2007)

A diminuição dos custos vem, em grande parte, pela mitigação dos custos relativos às falhas. Um produto que falha em sua fase de desenvolvimento gerará custos bem menores do que se essa mesma falha ocorresse durante a fase de uso do consumidor. De fato, o custo por falha aumenta exponencialmente ao passar da fase de desenvolvimento, para a fase de produção e para a fase de uso (Figura 2). O que se paga para corrigir uma falha é mais do que para prevenila. 


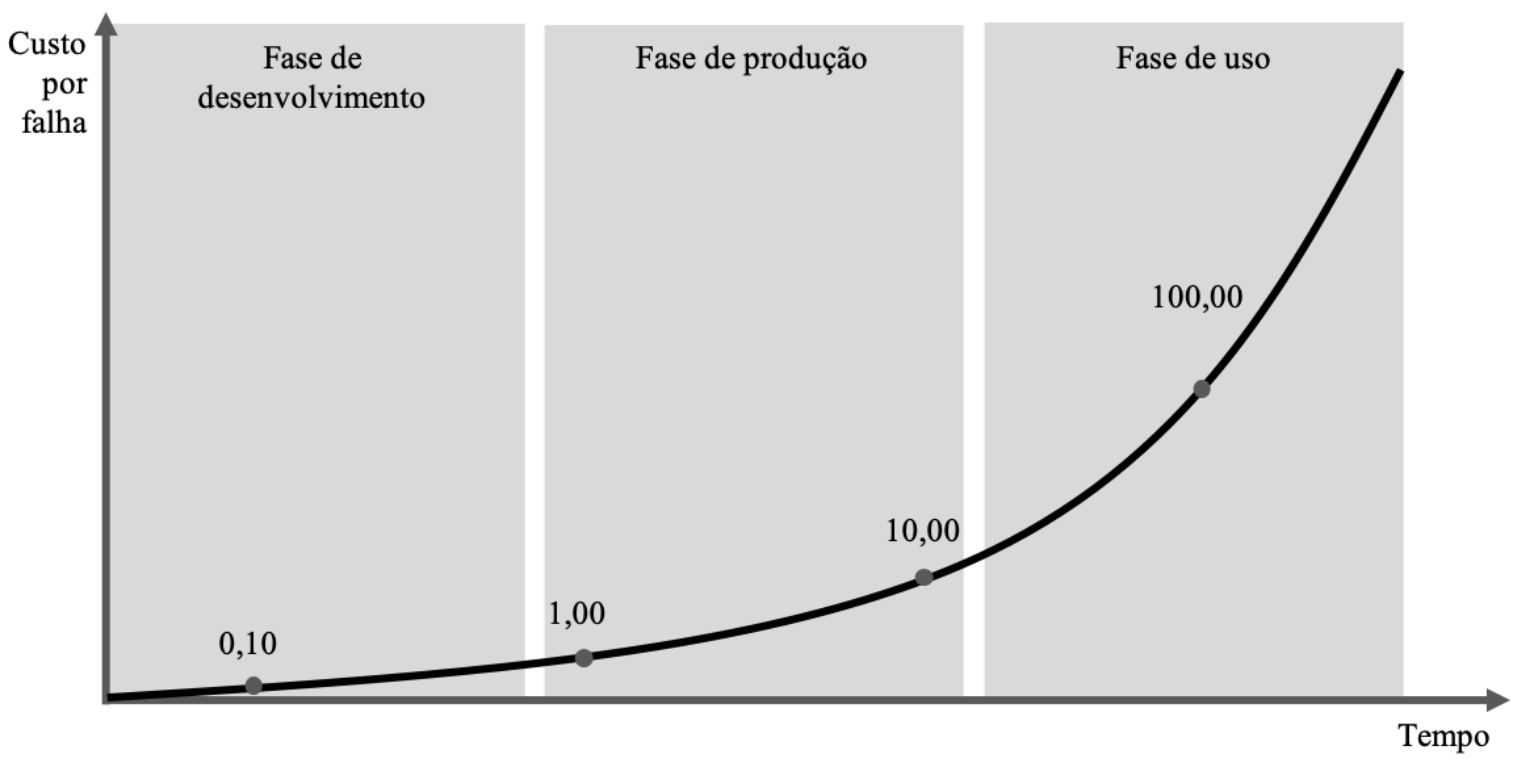

FIGURA 2 - Aumento do custo por falha ao longo das fases do produto. Fonte: Adaptado de Pahl, Beitz, et al.

Deve-se buscar o nível ótimo de qualidade do produto, reduzindo os custos devido a falhas e melhorias de qualidade (como a necessidade de processos mais precisos, pessoal mais capacitado ou em materiais mais "nobres"). Pode-se dizer que, à medida que se investe mais em qualidade, o custo devido a falhas decresce. Entretanto, o custo da qualidade aumenta exponencialmente e, por isso, atingir 100\% de qualidade não é o ideal. O custo total é dado pela soma dos custos das falhas e dos custos de prevenção de falhas, como mostrado na figura 3. 


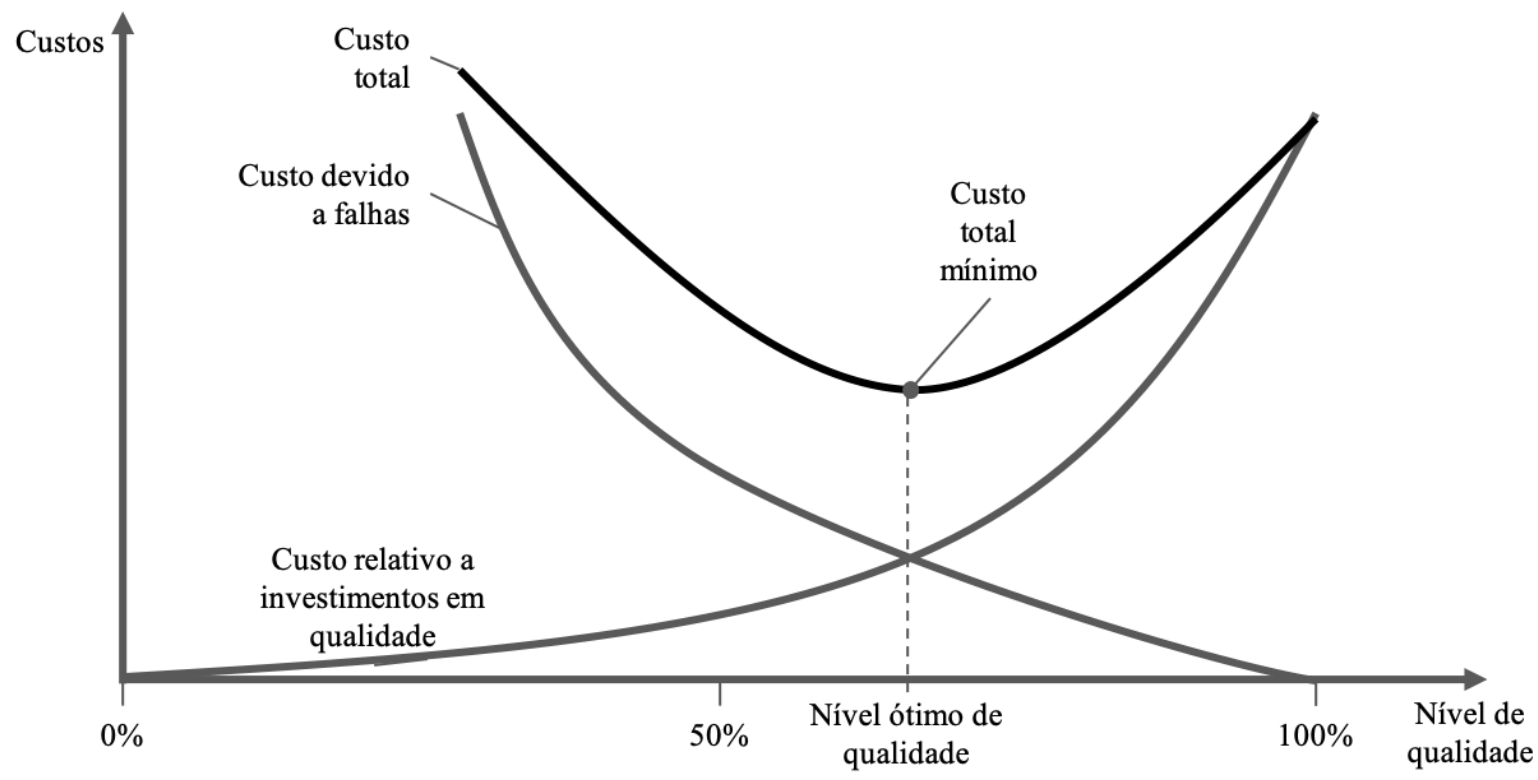

FIGURA 3 - Custo total em função do nível de qualidade do produto. Fonte: Adaptado de Pahl, Beitz, et al.

(2007)

Além dos aspectos de preço e qualidade, o lançamento do produto deve acompanhar as tendências do mercado, onde o aspecto velocidade também é majoritário. $\mathrm{O}$ time to market, deve ser o menor possível para diminuir a lacuna entre o surgimento de um produto em potencial no mercado e o início das vendas do produto para aproximar as vendas ao potencial do mercado (Figura 4).

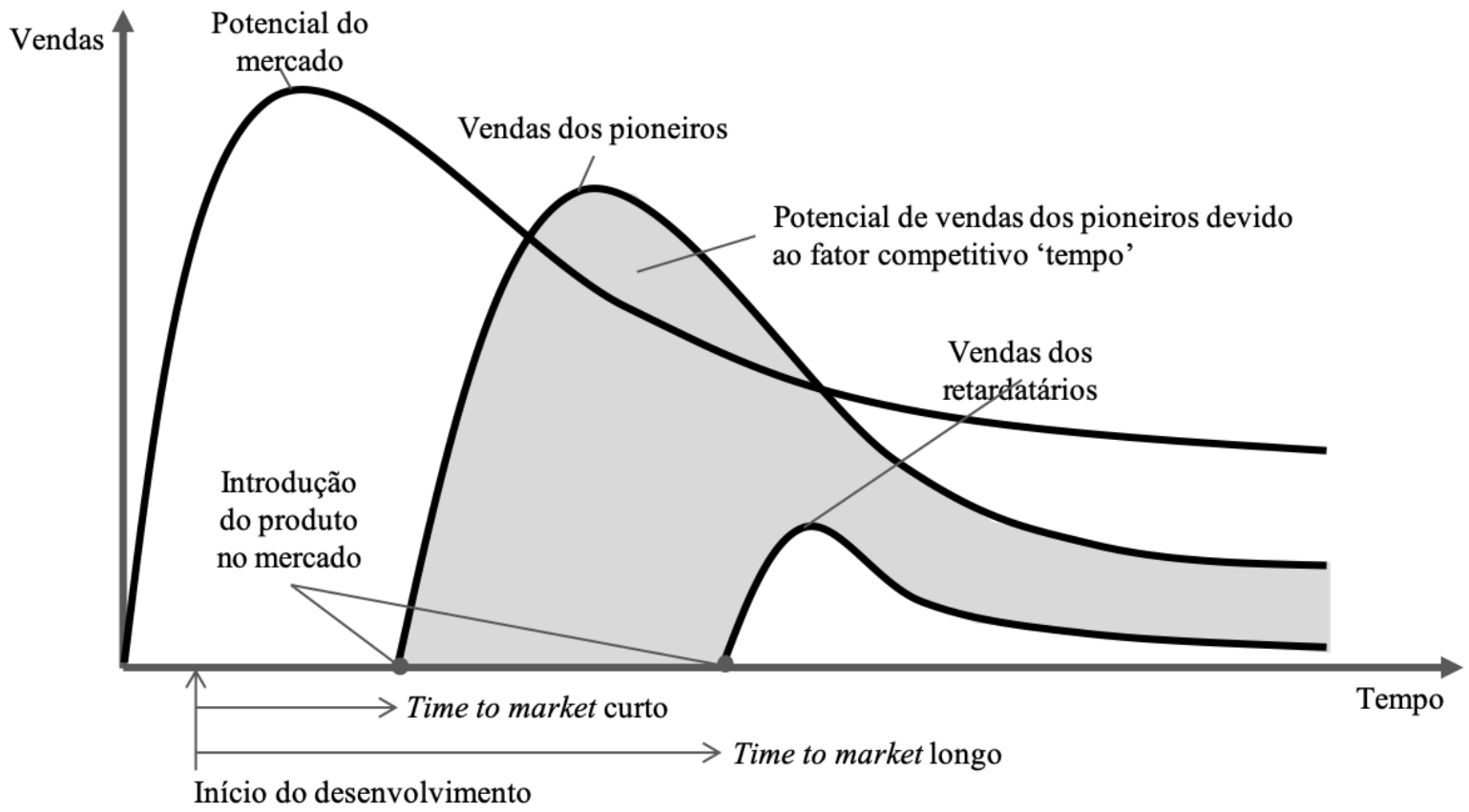


FIGURA 4 - Potencial de vendas relativos ao time to market. Fonte: Adaptado de Pahl, Beitz, et al. (2007)

Um bom projeto será aquele que reduzirá os custos de produção, evitará falhas tardias, gerará produtos com o nível qualidade que equilibra a satisfação do consumidor, os custos de qualidade e os custos devidos a falhas e, finalmente, diminuirá o tempo de desenvolvimento e produção para alcançar o maior potencial de vendas. Este deve ser o alvo ao se desenvolver um produto.

\subsection{Escola Clássica do PDP}

O desenvolvimento de um produto pode ser feito de formas variadas. Codinhoto (2003) resumiu propostas de seis autores para a divisão da etapa de desenvolvimento (Figura 5).

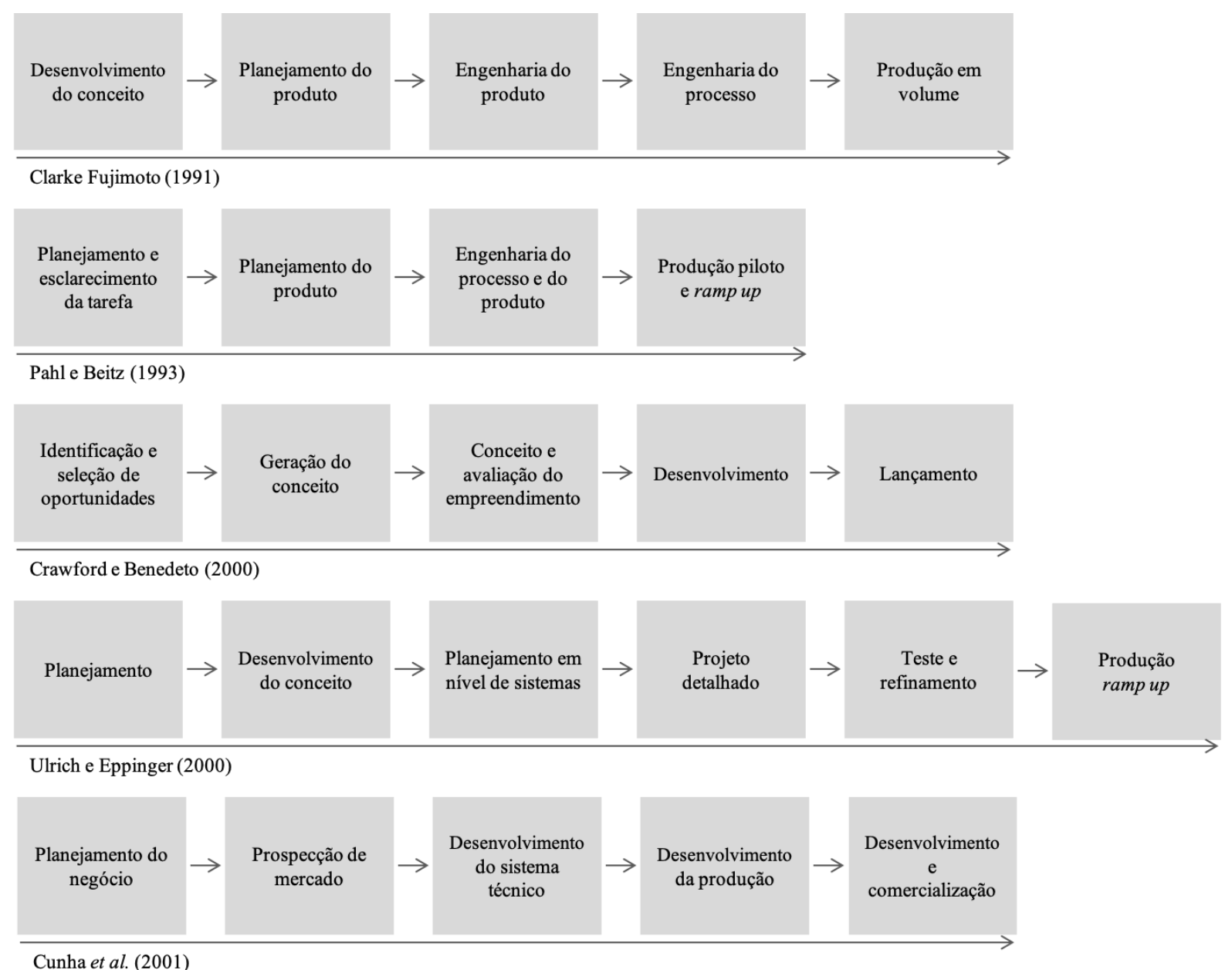

FIGURA 5 - Divisão do PDP em fases. Fonte: Adaptado de Codinhoto (2003) 
Contudo, há um consenso entre alguns autores que fundamenta o processo de desenvolvimento em três grandes grupos:

- Planejamento e concepção: Identificação de mercados em potencial, avaliação estratégica e de potencial técnico da empresa, identificação das necessidades dos clientes, compilação de variações de soluções e determinação do conceito do produto;

- Desenvolvimento: Determinação da arquitetura e do layout do produto, construção de protótipos e avaliação de soluções e

- Detalhamento: Representação e documentação das partes individuais.

É importante notar que as fases de Desenvolvimento e Detalhamento podem ocorrer simultaneamente, característica básica dos princípios de Engenharia Simultânea e dos Sistemas Integrados de Manufatura (ROMEIRO, 2015).

\subsection{Metodologia Sprint}

Com o avanço da tecnologia, o século XXI trouxe uma nova perspectiva: o intenso uso da internet no mundo dos negócios. A internet é uma terra fértil para novas ideias e, ao usufruir dos seus benefícios, pequenas iniciativas se tornaram negócios multimilionários. Muitas dessas iniciativas se transformam em startups, empresas focadas em solucionar problemas específicos e em transformar a solução em um produto rentável (ROBEHMED, 2013). Uma de suas características marcantes é a velocidade na qual os seus projetos são desenvolvidos. O tempo de idealização, elaboração, validação e lançamento do produto ou serviço deve ser o menor possível para garantir sua participação no mercado. Sendo assim, novas metodologias de projeto de desenvolvimento de produtos têm surgido para atender essas demandas.

"É difícil encontrar boas ideias. E mesmo as melhores encontram um caminho de incertezas em direção ao mundo real.” (KNAPP, 2016). Transformar ideias em produtos ou serviços de sucesso é um grande desafio. Afim de facilitar o processo de concepção, o autor desenvolveu uma metodologia baseada em ciclos de trabalho de cinco passos, um em cada dia (Figura 6): Entender e Definir; Divergir; Decidir; Prototipar e Validar. Ao final de uma semana, o grupo de trabalho terá completado um ciclo de desenvolvimento de uma ideia, produto ou serviço. Pode-se decidir fazer mais um ciclo ou interromper o processo e usar o que foi alcançado até então. 


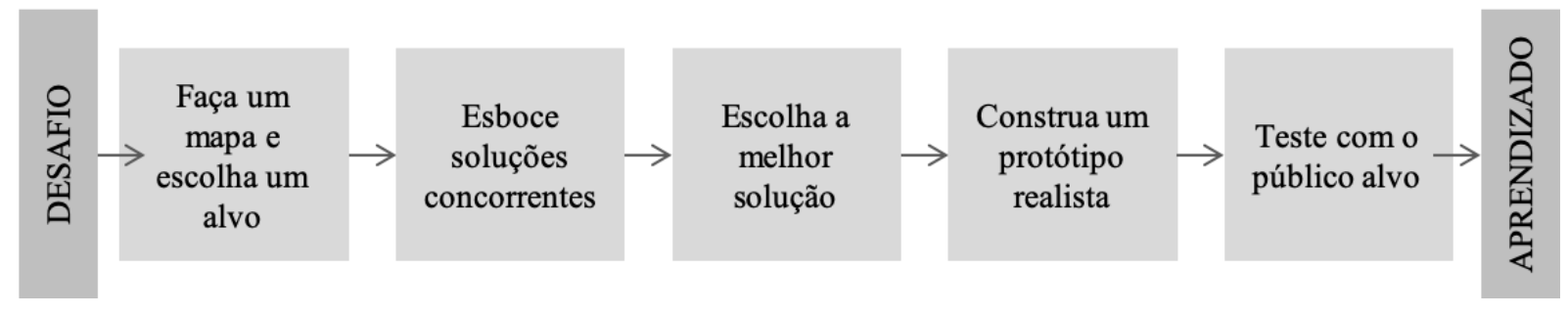

FIGURA 6 - Metodologia Sprint. Fonte: Adaptado de Knapp (2016)

A principal vantagem desse processo de cinco dias é que ao invés de esperar para lançar um MVP (Minimum Viable Product, ou Mínimo Produto Viável, que é desenvolvido ao menor custo possível, para testar o negócio antes de aportar grandes investimentos) para descobrir se a ideia é boa ou não, processo esse que pode tomar vários meses, o Design Sprint foca especificamente na validação da ideia com usuários e encurta o processo para 40 horas de trabalho.

\section{O MÉTODO PROPOSTO}

O objetivo deste trabalho é demonstrar a elaboração de um método de desenvolvimento de produtos de baixa complexidade e essa seção descreve o processo usado para tal. Primeiramente, tomou-se como base o procedimento dos alemães Gerhard Pahl e Wolfgang Beitz (1996) e do americano Jake Knapp (2016). Cada elemento dessas duas metodologias que é pertinente ao objetivo do trabalho foi tomado como nota. A metodologia proposta se divide em três grandes etapas, ou grupos de fases do projeto:

- Identificação de uma dor de mercado;

- Concepção e

- Desenvolvimento e Detalhamento.

As fases são os blocos de construção do projeto. Consequentemente, é de suma importância que elas estejam bem definidas: quais são seus dados de entrada, quais são seus métodos e o que se espera produzir. Para melhor compreensão, a Figura 7 mostra o procedimento da metodologia proposta de forma gráfica expondo as fases do projeto e suas respectivas etapas. 


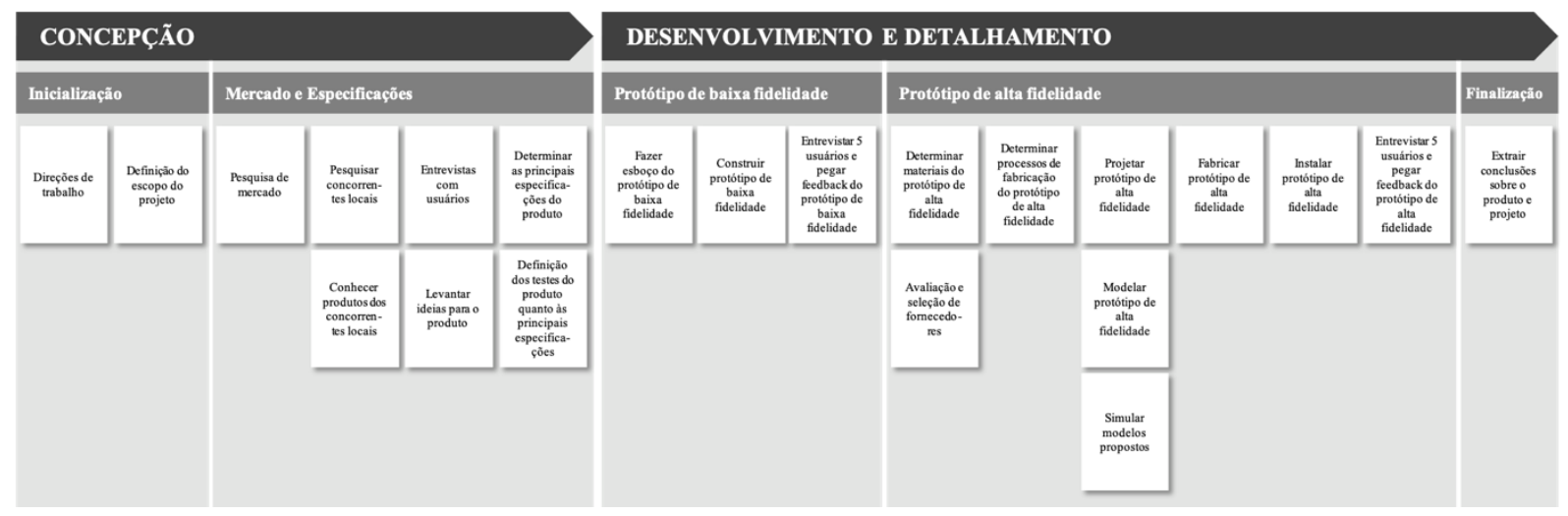

FIGURA 7 - Metodologia proposta de desenvolvimento de produtos de baixa complexidade.

As fases devem acontecer da esquerda para a direita. As fases que se encontram uma sobre as outras podem ser desenvolvidas simultaneamente. As etapas e suas respectivas fases serão expostas a seguir.

\subsection{Identificação de uma Dor de Mercado}

Antes de haver um projeto é necessário identificar uma "dor de mercado", ou seja, uma necessidade cuja solução os usuários estão dispostos a pagar. A complexidade da dor, a necessidade de uma solução e o número de interessados nessa solução determinam o potencial de vendas no mercado. Portanto, o passo preliminar à inicialização do projeto é detectar uma dor de mercado cujo potencial de vendas valha o investimento no projeto.

\subsection{Concepção}

Não se pode criar uma solução se não há uma tarefa bem definida. Concepção (Figura 8) é a etapa inicial do projeto e se ocupa em determinar seu escopo assim como as principais especificações do produto. Para tanto, é necessário que o mercado e a concorrência sejam estudados, que os usuários sejam ouvidos e que algumas ideias iniciais sejam levantadas. A etapa de Concepção se divide em dois grupos menores de fases:

- Inicialização e

- Mercado e Especificações. 


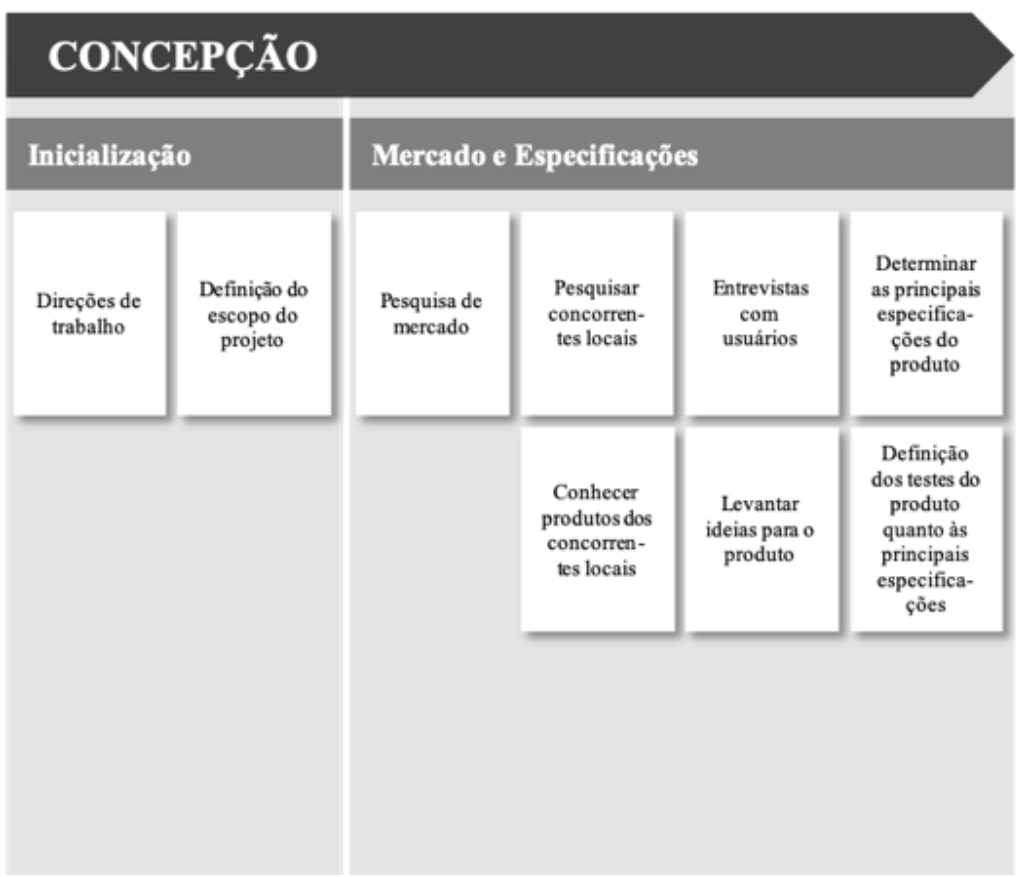

Figura 8. Etapa de Concepção

\section{Inicialização}

Para que o projeto seja inicializado, é necessário que se crie um grupo de trabalho e que as direções de trabalho sejam estabelecidas. Isso que dizer:

- Definir a liderança do projeto,

- Definir o mercado alvo,

- Definir de forma aproximada a verba do projeto e

- Definir de forma aproximada a linha do tempo do projeto.

Além disso, o escopo do projeto deve ser estabelecido: qual produto e em qual extensão. Pode-se desejar um produto para uso interno ou para uso externo, por exemplo. Dependendo da decisão, o produto pode ser completamente alterado. O Escopo deve responder as seguintes perguntas:

- O que será desenvolvido?

- Qual é o mercado?

- Qual é o orçamento do projeto de desenvolvimento?

- Qual é o prazo de entrega do produto acabado ao mercado?

- Quais são os requisitos legais em relação ao produto? Há patentes envolvidas? 
O primeiro passo deste bloco é estudar o mercado no qual o produto se insere. Por meio de pesquisas e entrevistas, por exemplo, deve-se verificar qual é o tamanho do público-alvo e se ele atende às ambições do projeto. Deve-se verificar também quem é a concorrência, quais produtos semelhantes existem no mercado e a qual preço eles são vendidos. Tal verificação dará uma boa noção sobre o próprio produto. É importante conhecer bem a concorrência para localizar o lugar do produto no mercado; se ele será mais barato e de qualidade mais baixa ou se ele atendará um público mais exigente que está disposto a pagar mais caro; se seu principal cliente será outras empresas ou os usuários finais; se o produto terá uma abrangência local, estadual ou nacional etc.

O produto deve ser concebido e desenvolvido em todas as etapas com o foco no consumidor final. A sua satisfação irá determinar o sucesso do produto. Sendo assim, deve-se estudar o mercado afim de levantar seus requisitos. Como descrito na Revisão de Literatura, pode-se valer de questionários, de métodos de associação ou de análises do ambiente do produto. Aqui, a entrevista com os usuários foi escolhida para levantar os requisitos dos usuários. De posse de todas essas informações, pode-se determinar as principais especificações do produto. Elas dizem respeito ao seu modo de operação, a como ele interage com o usuário e com o ambiente que o cerca. Neste bloco, dá-se início à busca por soluções para os desafios técnicos. Deve-se levar em conta viabilidade técnica e econômica das soluções propostas, assim como os alvos relacionados à qualidade e ao meio ambiente.

É importante que, para cada especificação definida, haja um teste para medi-la. Só assim será possível saber se o projeto logrou êxito ou não. De nada adianta colocar requisitos ao produto se ao final do processo de desenvolvimento não verificar se eles foram cumpridos. A definição dos testes do produto ocorre simultaneamente com as especificações do produto. À medida que as especificações forem sendo conhecidas, os testes devem ser definidos. Aqui o ideal é que os resultados sejam mensuráveis para facilitar a comparação. Caso não seja possível, deve-se definir padrões.

\subsection{Desenvolvimento e Detalhamento}

De posse das especificações do produto, pode-se iniciar a etapa de Desenvolvimento e Detalhamento. Essa etapa consiste na construção de protótipos de baixa e de alta fidelidade e na finalização do projeto (Figura 9). 


\section{DESENVOLVIMENTO E DETALHAMENTO}

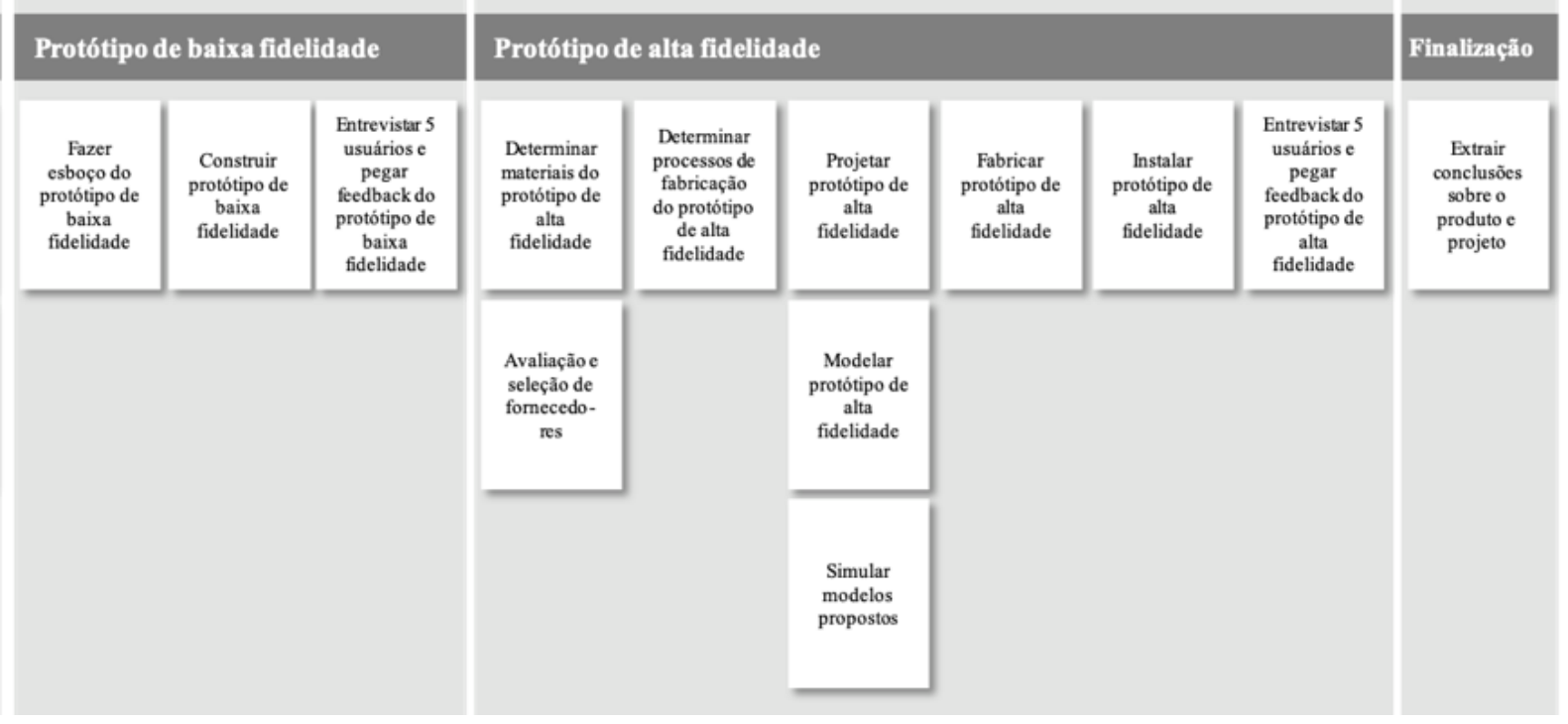

Figura 9. Desenvolvimento e detalhamento

\section{Protótipo de Baixa Fidelidade}

O propósito de se criar um protótipo de baixa fidelidade é verificar se as soluções preliminares atendem às necessidades dos usuários. Por isso, o foco aqui está na experiência do usuário, como ele percebe o produto. O nível de qualidade do protótipo deve ser o suficiente para simular o uso do produto sem consumir muito tempo e recursos.

A construção do protótipo de baixa de fidelidade pode ser feita, por exemplo, com materiais de fácil manipulação e baixo custo, ou com componentes específicos como aqueles utilizados para simular componentes eletrônicos, como a placa Arduíno. Essa placa é facilmente programável e pode desempenhar inúmeras funções ao conectar componentes como motores, sensores, luzes LED etc. Já para a prototipagem de aplicativos para smartphones, pode-se utilizar o Microsoft PowerPoint, o Keynote da Apple ou programas próprios para esse fim, como o Adobe XD. A ideia nesta etapa, dentro do conceito de MVP, é simular funções ou aspectos do produto (ou serviço) ao menor custo e tempo possíveis. As fases do Protótipo de Baixa Fidelidade são: Fazer o esboço do protótipo, construí-lo e entrevistar cinco usuários para entender sua relação com o produto. 
As entrevistas devem ser conduzidas afim de captar as reações do usuário ao produto. A intenção não é vendê-lo, mas fazer perguntas chave que permitirão entender quais reações o produto despertou no usuário, as primeiras impressões e quais são os pontos fortes e fracos, visando avaliação para posterior melhoria, servindo de base para apresentação e entrevistas junto a potenciais usuários. Não é necessário que muitas pessoas sejam entrevistadas. A experiência demonstrou que um grupo restrito de pessoas que representam o grupo de usuários fornecerão uma boa base de informações. Mas é importante escolher os entrevistados corretamente. Eles devem se enquadrar no perfil previsto dos usuários e serem capazes de entender as perguntas, respondê-las e serem sinceros e abertos quanto aos comentários. A partir do que se obteve nas entrevistas, o projeto do produto pode ser alterado afim de adequá-lo às expectativas do usuário. Dessa forma, o protótipo de alta fidelidade estará mais próximo ao ideal sem que muitos recursos tenham sido despendidos.

\section{Protótipo de Alta Fidelidade}

Diferentemente do protótipo de baixa fidelidade, o de alta fidelidade visa verificar não somente o ponto de vista do usuário, mas também o da produção de forma geral. Aspectos como: quais materiais serão usados, de quais fornecedores e quais processos de fabricação são aqui contemplados. Ao partir para uma fidelidade maior ao produto, será possível verificar aspectos econômicos, técnicos e de logística. O custo alvo pode ser atingido? As técnicas propostas são factíveis? Quais aspectos da produção devem ser observados? Essas são algumas perguntas que serão respondidas.

A avaliação dos fornecedores é importante para definir os materiais e o método de fabricação das peças. Dependendo da disponibilidade e do preço, pode ser necessário mudar o design de algum componente. Definidos os fornecedores e os materiais das peças, deve-se definir os métodos de fabricação de cada peça. É possível que seja mais viável economicamente terceirizar a fabricação de uma peça. Neste caso, a liderança do projeto deve tomar uma decisão para mudar a estratégia. Depois de selecionados os materiais, fornecedores e processos de fabricação além de considerar os feedbacks relativos ao protótipo de baixa fidelidade, a equipe de desenvolvimento está apta para projetar o produto em detalhes.

Afim de otimizar os custos relativos à fabricação e aos testes de protótipos, deve-se projetar e testar primeiramente modelos virtuais. Existem diversas ferramentas de projeto e simulação 
disponíveis no mercado. Deve-se escolher uma que seja adequada à aplicação do produto. A simulação deve levar em consideração os materiais e processos de fabricação. Após a aprovação do modelo virtual, pode-se partir para o físico. As especificações do produto são verificadas no protótipo físico de alta fidelidade por meio dos testes anteriormente estabelecidos. Após os testes, a amostra pode passar por um processo de otimização do seu design. Mesmo que as especificações foram cumpridas é desejável melhorar o desempenho de algum componente ou torná-lo mais barato.

Com o novo projeto otimizado, os componentes em seu design final são fabricados. É importante neste bloco validar os métodos de fabricação. Deve-se avaliar a qualidade do item produzido, os prazos de entrega, o preço de fabricação, os impactos ambientais e sociais gerados etc. $\mathrm{O}$ foco não deve estar somente no produto mas também na produção. Assim como feito como o protótipo de baixa fidelidade, é interessante fazer uma rodada de entrevistas com os usuários para saber suas opiniões.

\section{Finalização}

O último bloco do Processo de Desenvolvimento de um Produto pode ser o primeiro da sua produção. Geralmente o primeiro bloco da Produção é o chamado ramp up, que é uma simulação progressiva da produção que aumenta o seu volume de produção até que ele chegue ao que será o volume real de produção. Em todo caso, é importante que o processo de desenvolvimento seja avaliado, assim como o próprio produto. As direções de trabalho foram respeitadas? Os requisitos do produto foram atingidos? Uma resposta negativa pode colocar todo o projeto em xeque e cabe à liderança decidir o próximo passo. O importante é que sempre haverão aprendizados. Lições podem ser tiradas para que haja uma melhoria contínua nos projetos.

\section{CONCLUSÃO}

O desenvolvimento de um método de desenvolvimento de produtos de baixa complexidade, voltado para pequenas empresas industriais apresenta-se como uma demanda importante em termos de relevância social, tendo em vista o relevante papel dessas empresas para a geração de empregos. $\mathrm{O}$ fato dessas empresas normalmente não terem acesso a ferramentas sofisticadas de projeto não é necessariamente um aspecto negativo, visto que estas ferramentas foram em sua maioria desenvolvidas para grandes empresas. Por outro lado, a aplicação de métodos 
originalmente desenvolvidos para startups nem sempre atende às necessidades e características dos projetos desenvolvidos.

Visando atender a esta demanda, este trabalho apresentou de forma conceitual uma proposta de método que cobre os passos necessários para iniciar um projeto, estudar o mercado, determinar as especificações do produto e construir protótipos de alta e baixa fidelidade, de forma a auxiliar pequenas empresas interessadas no desenvolvimento de novos produtos. $\mathrm{O}$ estudo procurou definir as fases consideradas necessárias e relevantes ao processo, tendo em vista características específicas das empresas e do nível de complexidade do produto desenvolvido.

Acredita-se que o método não se apresenta como prescritivo, mas sim como uma série de recomendações que podem ser adotadas (em todo ou em parte) de forma consistente e progressiva por pequenas ou médias empresas, por não representarem grandes custos financeiros ou a implementação de soluções tecnológica ou organizacionalmente complexas.

\section{AGRADECIMENTOS}

\section{SUPRIMIDO VISANDO AVALIAÇÃO CEGA}

\section{REFERÊECIAS}

BOOZ, A. New Products Management for the 1980s. New York: Booz, Allen \& Hamilton, 1982.

CODINHOTO, R. Diretrizes para o Planejamento e Controle Integrado dos Processos de Projeto e Produção na Construção Civil. Porto Alegre: PPGEC/UFRGS, 2003.

COOPER, R. G. The impact of new product strategies. Industrial Market Management, 12, n. 4, 1983. 243256.

CROSS, N. Engineering design methods: strategies for product design. 2nd ed. ed. London: Wiley, 1994.

JONES, J.C. Design methods. Chichester: John Wiley, 1970.

KNAPP, J. Sprint: O método usado pelo Google para testar e aplicar novas ideias em apenas cinco dias. 1a Edição. ed. Rio de Janeiro: Intrínseca, 2016.

PAHL, G. et al. Engineering Design - A Systematic Approach. 3. ed. ed. London: Springer, 2007.

PAHL, G.; BEITZ, W. Engineering Design: A Systematic Approach. London: Springer-Verlag, 1996.

ROBEHMED, N. What is a startup? Forbes, 2013. Disponivel em:

<https://www.forbes.com/sites/natalierobehmed/2013/12/16/what-is-a-startup/\#657e9ead4044>. Acesso em: 28 março 2019. 
ROMEIRO FILHO, E. FERREIRA, C.V., GOUVINHAS, R.P.; NAVEIRO, R.M.; CAUCHICK, P. Projeto do Produto. Rio de Janeiro: Elsevier, 2010

ROMEIRO FILHO, E. Sistemas Integrados de Manufatura - para Gerentes, Engenheiros e Designers. São Paulo: Atlas, 2015

ULRICH, K. T.; EPPINGER, S. T. Product Design and Development. International Edition. ed. Boston: McGraw-Hill, 2000.

WORLD HEALTH ORGANIZATION. World Health Organization. WHO. Disponivel em: $<$ http://www.who.int/dietphysicalactivity/pa/en/>. Acesso em: 10 setembro 2018. 